\title{
PROMOTING LOCAL ECONOMIC DEVELOPMENT IN CITIES OF DEVELOPING COUNTRIES THROUGH INFORMAL SECTOR ECONOMIC POTENTIALS: AN ANALYSIS OF OBSTACLES AND THEIR ROOT CAUSES IN THE CONTEXT OF DODOMA CITY IN TANZANIA
}

\author{
Daniel Wandera Clief Naku \\ Academician, Researcher \& Consultant, Department of Geography, \\ St John's University of Tanzania - East Africa.
}

DOI: 10.46609/IJSSER.2020.v05i04.010 URL: https://doi.org/10.46609/IJSSER.2020.v05i04.010

\begin{abstract}
Literature shows that the informal sector is a major player in employment creation, goods and service provision as well as a source of income in many cities of developing countries. These aspects among others constitute economic potentials from the informal sector. Through these potentials as reflected in literature, the informal sector is expected to contribute to local economic development in cities where the sector is pre-dominantly prevalent especially in developing countries. Unfortunately, realizing the contribution of these potentials to local economic development in such cities remains to be much of a myth than a reality. There are several obstacles that continue to make it difficult for these economic potentials to actually contribute to local economic development in these cities and at the same time, these obstacles are seen to emanate from various root causes. In view of this challenge, this paper through an empirical study examined these obstacles and their root causes in the context of Dodoma City which appears to be a rapidly growing city in Tanzania.
\end{abstract}

Keywords: Developing Countries, Economic Potentials, Informal Sector, Local Economic Development \& Obstacles

\section{INTRODUCTION}

Unlike in the developed countries where economies of cities much depend on the formal sector to boost their economic development, economies of cities in developing countries still depend on both the formal and informal sectors. In some instances the informal sector is even larger than 


\section{International Journal of Social Science and Economic Research}

ISSN: $2455-8834$

Volume: 05, Issue: 04 "April 2020"

the formal sector in particular cities. This implies that in developing countries, the informal sector still has a role to play in terms of promoting local economic development in such cities. In Nigeria, a study by Onwe, (2013) revealed that the informal sector is continuously expanding in developing countries, and has been serving as a 'safety belt' in providing employment and income to the teaming poor. In Kenya, according to Kempe (2013), the informal economy now constitutes an important component in the economic activities and process of development in Kenya.

In Tanzania like any other developing nation, the role of the informal sector in promoting local economic development cannot be under estimated. According to a study by ILO, UNIDO and UNDP (2002) the informal sector in Tanzania needs not only to be taken as a seedbed for small enterprise, rather it is a solution of last resort for many and in particular for poorer female heads of households who cannot find a job to pay them a living wage. The sector is seen as an inclusive gate pass for many to engage in development matters, hence supporting the country's 2025 development vision that states

'Tanzania should have created a strong, diversified, resilient and competitive economy, which can effectively cope with the challenges of development, and which can also easily and confidently adapt to the changing market and technological conditions in the regional and global economy'.

In fact according to Mia et al, (2017) as cited in Diao et al (2016), between 2002 and 2012 Tanzania's economy grew more rapidly than at any other time in its history. However, only 11.4 per cent of employment growth occurred in the formal private sector while the remaining 88.6 percent occurred in the informal sector.

On the basis of the above literature, it is evident that informal sectors have a significant role they can play towards realizing development efforts in any country especially in the developing countries. From the economic point of view as noted from the above literature, are not only creating employment opportunities but also seen as an inclusive gate pass for many of the poor and disadvantaged communities to engage in economic development matters that impact them and have influence to their lives. This study therefore seeks to explore this matter at a relatively small scale level of a city as opposed to the national level which has always been the norm of analysis for most research.

\section{PROBLEM DEFINITION}

As revealed in literature, the informal sector through its economic potentials is expected to make contribution to local economic development in cities where it is being practiced such as cities in 


\section{International Journal of Social Science and Economic Research}

ISSN: $2455-8834$

Volume: 05, Issue: 04 "April 2020"

developing countries. Unfortunately, realizing this contribution remains to be much of a myth than a reality in most of the cities. There are several obstacles that continue to make it difficult for these economic potentials to indeed contribute to local economic development in these cities and at the same time, these obstacles are seen to stem from various root causes. In view of this challenge, this paper through an empirical study examined these obstacles and their root causes in the context of Dodoma City in Tanzania.

\section{LITERATURE}

As pointed out by Misati (2007), there are competing views from scholars on the role of the informal sector in promoting local economic development. While other scholars argue that the informal sector impedes effort towards promoting local economic development due to the fact that businesses that operate outside the tax and regulatory net have a hard time accessing credit, limiting the scale of their operations and exploitation of investment opportunities.

Moreover, the informal economic activities are also said to undermine the ability of governments to raise revenue and therefore deny the public sector resources that would otherwise play a complementary role to private investment through infrastructural development or facilitation of business environment.

On the other hand, other studies view informal employment as a lifeline for the poor or as a legitimate response to over-burdensome regulation, implying positive relationships between the informal sector and investment (ibid).

In this case, the informal sector provides the economy with a dynamic and entrepreneurial spirit, which in turn can lead to more competition, innovation, higher efficiency and increased investment (Schneider and Klingmair, 2004).

According to Barro (2000), the existence of the informal market makes it possible for agents to engage in entrepreneurship or to obtain scarce goods and services that otherwise would not exist.

In addition, Madziakapita (2003) argues that the informal sector helps to absorb labour of new arrivals in the urban areas. Without the existence of the informal sector, it is likely that a 'social economic crisis' can emerge hence destabilizing the whole society in general. As opposed to the formal sector, the informal sector capably creates a large number of jobs at a very low capital cost because it does not incur extra costs such as employment benefits.

In Nigeria, a study by Onwe, (2013) revealed that informal sector is continuously expanding in developing countries, and has been serving as a 'safety belt' in providing employment and 


\section{International Journal of Social Science and Economic Research}

ISSN: $2455-8834$

Volume: 05, Issue: 04 "April 2020"

income to the teaming poor. The author further reveals that in terms of contributions to national output, it has been observed that, despite an existing low productivity in the informal sector, the sector accounts for a sizable percentage of the Gross Domestic Product (GDP) in developing countries.

In Kenya, according to Kempe (2013), the informal economy now constitutes an important component in the economic activities and process of development in Kenya.

According to the author, although its relative importance was minimized in the past, the informal economy continues to thrive in Kenya and the rest of Africa. In Uganda, according to Muwonge et al., (2007), the informal sector is playing a vital role of job creation to many Ugandans. In fact according to the authors, regardless of the definition, there is sufficient proof that the sector is important to the developing world. The 2001/2002 Uganda Businesses Register reported that the informal sector constituted of 150, 138 businesses which is $87 \%$ of the total 160,883 businesses registered during that time.

\subsection{Tanzania Scenario: Informal Sector Contribution to Local Economic Development in Cities}

Just like in any other developing country, the informal sector in Tanzania accommodates many people in terms of job creation. According to REPOA (2013), in Tanzania, the 2009 Diagnosis Report on the Property and Business Formalization Programme (MKURABITA) reported that $97 \%$ of all businesses in Tanzania and $86 \%$ of all urban properties in Tanzania are extralegal.

In addition, the 1991 Rural and Urban Informal Sector Study revealed that the informal sector was a source of basic goods and services which were relatively cheaper, appropriate and easily accessible to the majority of low-income earners. At the time of the survey the informal sector output was equivalent to over $10 \%$ of GDP, more than the total estimated annual gross output of the whole parastatal sector. Consequently, the 2008 study by ILO found a wide variation in the sectoral distribution of the informal sector activities but a high concentration of approximately $65 \%$ of the informal sector enterprises being in wholesale and retail trade (ILO 2009).

In terms of ownership of the informal sector enterprises, the ILO survey of 2008 found that it is almost equally divided between male and females. The survey revealed that men own $52 \%$ of the enterprises, while women own $48 \%$. In addition, the survey further showed that about $57.4 \%$ of the total informal sector labour force is generated by male owned enterprises while $42.6 \%$ is generated by female owned enterprises. 
International Journal of Social Science and Economic Research

ISSN: $2455-8834$

Volume: 05, Issue: 04 "April 2020"

Categorically, the REPOA report (2013) further reveals that the 1991 survey showed that the sector was the source of employment for 2,369,380 people; (1,531,094 males and 838, 2860 females) constituting $22 \%$ of total employment. Operators constituted $73.6 \%$ of the total informal sector employed. Half were engaged in trade/restaurants/hotels industry, followed by manufacturing (22\%) and in urban areas agriculture and fishing were $10 \%$. Females were dominant in trade/restaurants/hotels while males were predominant in mining, construction and transport industries. By 2006, according to the Integrated Labour Force Survey, $40 \%$ of all households in Tanzania Mainland were in the informal sector activities. The urban informal sector employed 66 percent of the labour force as the main activity.

Generally, in the context of Tanzania and in relation to the prevailing literature, informal sector remains to be seen as one of the major contributors to economic development. The sector is predominant in urban areas which imply that urban areas such as cities benefit from it in various ways and this contributes to their economic development process.

\section{METHODOLOGY}

The study employed a Case Study approach in which Dodoma City was used as a Case Study area. A total of 60 informal business operators within Dodoma from five business categories were explored. These businesses were in the categories of Saloons, Groceries, Metal Welding, Furniture and Carpentry as well as Restaurants commonly referred to as Mama-Lishe in the Swahili language. Informality in this study was conceptualized to refer to all those business activities that were not legally registered. Data analysis entailed descriptive statistics and cross tabulation.

\section{RESULTS AND DISCUSSION}

This research sought to explore informal sector economic potentials obstacles and their root causes. This paper explored four informal sector economic potentials that include employment creation, income generation, other private investment establishments and absorbing new labour arrivals.

\subsection{Obstacles to Employment Creation as an Informal Sector Economic Potential}

Employment creation by the informal sector is seen as a key economic potential for promoting LED in any area as noted by scholars such as Tambo (2017), Abolade et al (2013), Repoa (2013) and Misat (2007). According to respondents in this research, employment creation as an economic potential of the informal sector in Dodoma City was largely hampered by a number of factors. These factors included lack of working area (5\%), limited capital (46.7\%), lack of access 
to loans $(26.7 \%)$ and low demand $(21.7 \%)$. Overall, $46.7 \%$ of the study respondents felt that limited capital to a great extent obstructed employment creation in this sector and thus limited the promotion of LED in Dodoma City. Figures 1 provides a summary of findings on the limiting factors to employment creation as an economic potential of the informal sector.

Fig 1: Employment Creation Obstacles

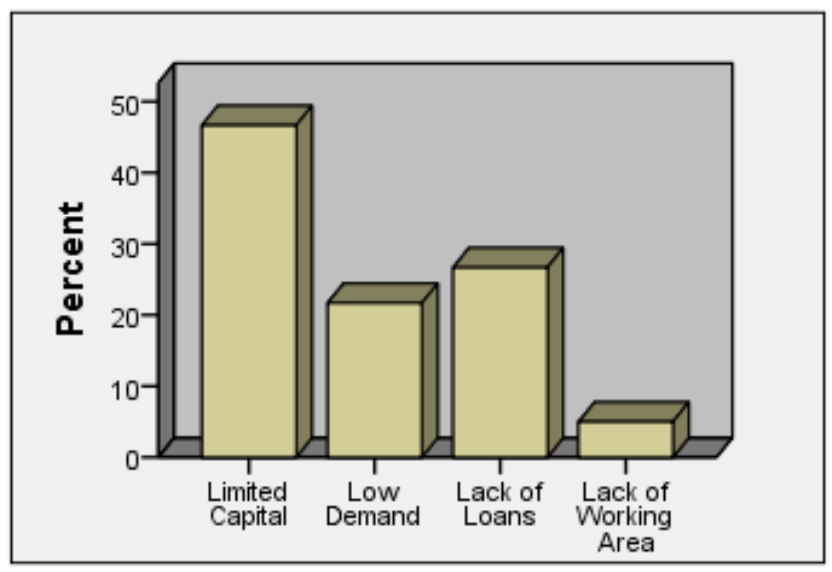

Source: Based on Author's Survey, 2019

Generally, according to the study respondents, this obstacle is mainly associated with two major root causes. First, the small nature of their businesses which do not provide enough in terms of income so that they could use the money employ more and increase their production. Secondly, the fact that the informal nature of their businesses does not give them the opportunity to access any funding such as loans. As a result according to the study respondents, they are left to struggle with how to make their businesses survive with the limited capital they get. For instance, one of the study respondents had this to say during the interview....

'I am struggling to operate my business because I don't have enough capital....so how can I even think of employing people that I won't manage to pay?

\subsection{Obstacles to Income Generation as an Informal Sector Economic Potential}

Income generation was one of the analyzed economic potentials of the informal sector activities and largely supported by authors such as Misat (2007), Onwe (2013) and Muwonge et al (2007).However, according to the findings of this study in the context of Dodoma City, this economic potential was hampered by a number of obstacles as revealed by the study respondents. These obstacles included low production $(26.7 \%)$, limited number of customers $(51.7 \%)$ and the increasing family needs to be met $(21.7 \%)$ as presented in Figure 2. 
Fig 2: Income Generation Obstacles

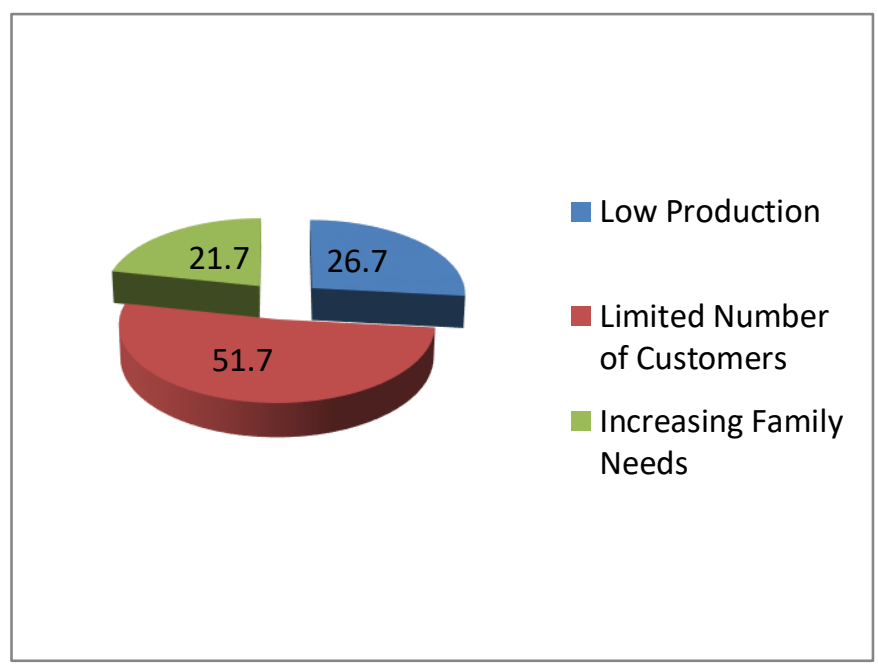

Source: Based on Author's Survey, 2019

According to study respondents, the root cause of this obstacle lies in the fact that the majority of the people engaged in this business lack the skills to attract customers and also operate in environments that are sometimes not attractive to customers. For instance one restaurant (mamalishe) operator stated that many people find it difficult to come to her business area because of the environment from which the business is conducted. In quotes...' I am operating from an environment that is not attractive to many people...If I had had enough money, I would have rented a better place because the food business is very good as everybody needs food to survive',.

Others felt it was about the low quality of goods and services they offer but this is again attributed to not having enough capital to produce the required high quality goods and services.

\subsection{Obstacles to Other Private Investment Establishment as an Informal Sector Economic Potential}

Authors such as Barro (2000) and Government of Kenya report (2002) claim that as people get engaged in informal business activities; they earn income which enables them to invest in other private investment establishments. These new investments then serve as economic potentials for promoting local economic development in cities. However, in the context of this study, this informal sector economic potential for the case of Dodoma city was found to be facing a number 
of obstacles that were limiting its level of contribution to local economic development in Dodoma city. These obstacles included little profit (15\%), limited skills (21.7\%), limited capital (48.3\%), lack of education $(6.7 \%)$ and no time to manage $(8.3 \%)$. As per these results, the aspect of limited capital was highlighted as a major obstacle as shown in Figure 3.

Fig 3: Income Generation Obstacles

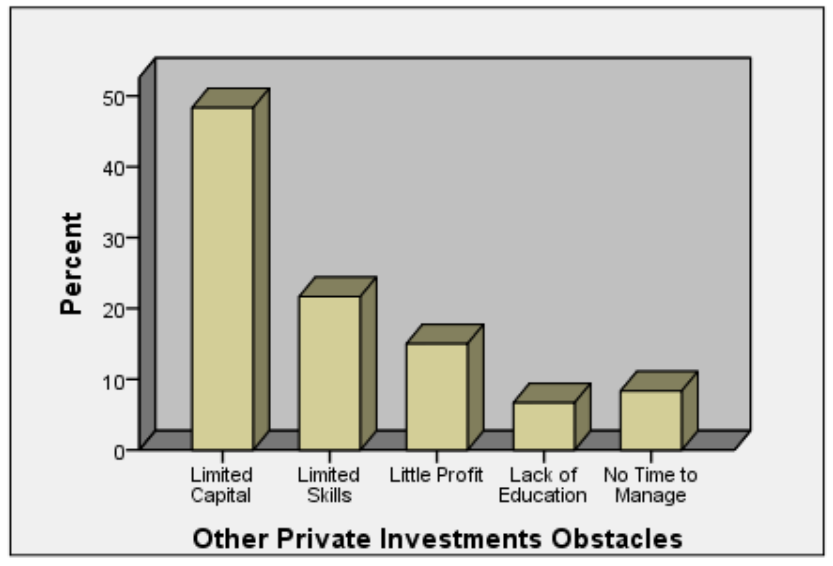

Source: Based on Author's Survey, 2019

Just like it had been revealed under the root cause for obstacles affecting employment creation, the noted root cause of limited capital as an obstacle to enhancing private investment establishment was found to be related to the small nature of the businesses whose production capacity was low and thus generated low income which would not allow those engaged in the informal sector activities to invest in other private investment activities. In addition, study respondents also pointed out that the profits from these businesses were very little and most of them operated at the marginal level, making no profit at all but struggling to sustain the business. Hence, in such situations, engaging in other private investment establishments was found to be very difficult for some of them.

\subsection{Obstacles to Absorbing New Labour Arrivals as an Informal Sector Economic Potential}

From literature as revealed by Madziakapita (2003), Misara and Alam (2014), absorbing new labour arrivals as one of the informal sector economic potentials can promote local economic development in cities such as Dodoma City. However, findings of this study revealed that, this economic potential was faced by a number of obstacles that may have hindered its contribution to this effect. These obstacles included the difficult to trust new labour arrivals by owners of the informal businesses (40\%), lack of experience (35\%), lack of skills $(8.3 \%)$ and the fact that new labour arrivals are always on the move and therefore considered not stable in jobs by owners of 
the informal businesses (16.7\%). As it can be noted from the statistics, majority of the respondents $(40 \%)$ felt that the major obstacle to absorbing new labour arrivals was associated with the difficult of trusting these new labour arrivals followed by the fact that they were considered not to have experience as presented in Figure 4.

Fig 4: Absorbing New Labour Arrivals Obstacles

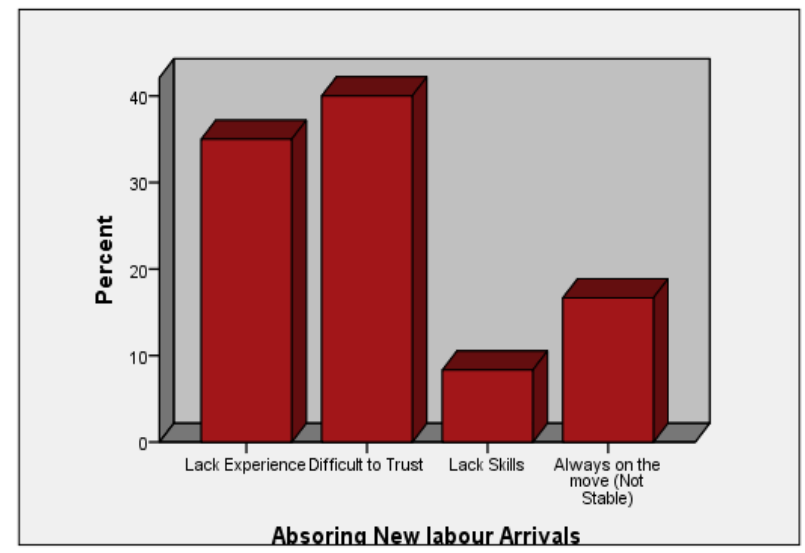

Source: Based on Author's Survey, 2019

As reflected in Figure 4, difficult to trust new labour arrivals was noted as a major obstacle to absorbing new labour arrivals among study respondents. This was largely on the account of past experiences that most of them had experienced. Such account was linked to some of the new recruited labourers arriving from various destinations stealing their money, properties and sharing information with competing business partners. One saloon operator lamented that he had lost property worth millions when one of the employees he had recruited from Tanga region decided to steal and disappear with some of his valuable properties. As such, this study noted that there was a high level of distrust for new labour arrivals in the sector and this has hampered the economic potential's contribution to local economic development in terms of creating jobs for new labour arrivals in Dodoma City.

\subsection{Synthesis of Obstacles Faced by Informal Sector Economic Potentials in their Contribution to LED in Dodoma City}

Overall, this part of the paper has explored obstacles facing informal sector economic potentials and thus limiting their level of contribution to local economic development in Dodoma City. Results clearly showed that there were a number of obstacles that had acted to this effect but some were more felt and greatly impacted the level of contribution to local economic development from the economic potentials as revealed by the study respondents. For instance, 
International Journal of Social Science and Economic Research

ISSN: $2455-8834$

Volume: 05, Issue: 04 "April 2020"

limited capital largely affected both employment creation and income generation while lack of trust for new labour arrivals affected absorbing of these new labour arrivals.

\section{CONCLUSION}

As depicted in literature, there is no doubt that the informal sector has a valuable contribution to the well being of the urban dwellers and consequently to local economic development. However, as revealed in this study, the ability of the informal sector through its economic potentials to contribute to local economic development in cities such as those in developing countries is largely undermined by the existence of a number of obstacles. Such obstacles as noted in the case of Dodoma city range from lack of capital to boast their businesses to distrust among business owners to new labour arrivals among others. This study went further to examine the root causes of such obstacles. Again as previously discussed in the findings, some of these root causes include the small nature of business that earn them very little income, lack of access to soft loans and limited business skills among others.

On the basis of such findings, it is of paramount importance to point out that unless these obstacles and their root causes are addressed, the contribution of the informal sector to local economic development through its economic potential will continue to be undermined. As a result, the sector will only end in being a hand to mouth sector with very little or no impact to the economic development of the cities in which such informal sector activities take place.

\section{RECOMMENDATIONS}

Study results showed that promoting local economic development in Dodoma city through informal sector economic potentials was low. However, these results were attributed to a number of obstacles that were revealed in the study. Considering the fact that the informal sector plays a vital role in urban economies of cities in most developing countries, this study recommended that Dodoma City needed to recognize this potential as per recommendations below.

\subsection{Initiating and Implementing Skills Development Programmes}

One of the revealed obstacles to the flourishing of informal business enterprises in Dodoma City so as to promote local economic development in the city was the lack of skills among informal business enterprise operators. This study therefore recommended that to successfully overcome this obstacle, the city with the assistance of its development stakeholders should engaged in designing and implementing skills development programs that would broaden the operational abilities of those engaged in the sector and also attract new operators. 
International Journal of Social Science and Economic Research

ISSN: $2455-8834$

Volume: 05, Issue: 04 "April 2020"

\subsection{Put emphasis on Growing and Expanding the Internal Market Base}

A lack of demand which is a proxy indicator for a lack of a viable market either internally or externally was reported to have been one of the obstacles to the operations of studied informal business enterprises. Dodoma's internal market needs to be broadened and this implies that the city needs to take on ad-hoc/deliberate measures to grow and expand its internal market base. For instance, employing strategies that would attract and retain people in the city so that they could become a part of the internal market base.

\subsection{Encouraging the Establishment of Informal Funding Sources such as Village Community Banking (VICOBA)}

Accessing funds through formal funding sources such as banks or any other financial institutions has proved to be a challenge and an expensive venture to many operators of informal business enterprises. In light of these challenges, a substitute in the form of informal funding sources has proved to be of relevance to business activities falling within this category. Hence, a possibility of further encouraging of people to establish these kinds of funding sources may be of help by easing access to the required funds so as to address the challenge of limited capital that was found to be the most pressing obstacle.

\section{REFERENCES}

1. Abolade, O, Adeboyejo, T, Kehinde \& Olamiju, O (2013): Contributions of Urban Informal Enterprises to the Economy of Ibadan, Nigeria, Global Journal of Human Social Science

2. Barro, R. J. (2000): "Rule of law, Democracy and Economic Performance"

3. Diao, X., J. Kweka, \& McMillan.M (2016). 'Economic Transformation in Africa from the Bottom up: Macro and Micro Evidence from Tanzania'. NBER Working Paper 22889. National Bureau of Economic Research Economics, Volume 13 Issue 5

4. ILO (2009). Working Conditions in the Informal Sector of Tanzania. Geneva: International Labour Organization. Incidence of Poverty in Nigeria

5. Kempe,R. H (2013). Informal economic activity in Kenya: benefits and drawbacks. Africa Geographical Review, Volume 33

6. Madziakapita, S.V. (2003): A situational Analysis of the Informal Sector in Three Major Cities (Blantyre, Lilongwe and Mzuzu) of Malawi. Unpublished Ph.D Thesis, University of Malawi

7. Mia.E, Margaret. M \& Jed.S (2017). Employment and productivity growth in Tanzania's service sector, WIDER Working Paper 2017/16, United Nations University 
8. Misara. P \& Alam.M (2014). Urban informal sector and migrants. Research Paoer ISSN No. 2347-856X.

9. Misati, R. N. (2007): The Role of Informal Sector in Investment in Sub-Saharan Africa. Submitted to ACDC for presentation in South Africa, Kenya Institute for Public Policy Research and Analysis, Nairobi, Kenya

10. Muwonge. A, Obwona. M and Nambwaayo. V (2015). Enhancing contributions of the informal sector to National development: The case of Uganda.

11. Onwe. O.J (2013): Role of the Informal Sector in Development of the Nigerian Economy: Output and Employment Approach. National Open University of Nigeria

12. REPOA (2013): Promoting Micro and Small Enterprises for Inclusive Development: Managing the Transition from Informal to Formal Enterprises. REPOA's $19^{\text {th }}$ Annual Research Workshop

13. Schneider, F \& Klinglmair.R (2004). "Shadow Economies Around the World: What Do We Know?" IZA Discussion Paper No. 1043 South Africa

14. Tambo, B (2017): Economic development through informal sector support, Centre for Development Research, University of Bonn, Germany

15. UNDP, ILO \& UNIDO (2002). Roadmap study of the informal sector in Mainland Tanzania. Dar es Salaam, April 2002. 